\section{Tribology textbook}

\section{Robert Schnurmann}

History of Tribology. By D. Dowson. Pp. 677. (Longman: London and New York, 1978.) $£ 35$.

IN 1964, the Rt Hon. the Lord Bowden of Chesterfield as Minister of State for Education and Science had asked $\mathrm{Mr} \mathrm{H}$. Peter Jost to set up a working party to report on lubrication research and teaching requirements. The academic world was represented on this working party by Professor Dowson. Before its findings were published in February, 1966, the "Jost Committee" had asked the editor of the Oxford Dictionary for a pithy name to summarise in one word the closely related subjects of Friction between Solid Bodies, Wear, and Lubrication, and he suggested 'Tribology'. Thus, HMSO published the report of the working party under the title Lubrication (Tribology), Education and Research-A Report on the Present Position and Industry's Needs which specifically mentioned "a conservative estimate" of the potential annual savings to British industry from improvements in education and research of "about $£ 515$ million, the biggest single item being savings in maintenance and replacement costs of $£ 230$ million".

This triggered off a spate of activity. Three centres of tribology were established in this country, two at Universities (Leeds and Swansea) and one in a government establishment (Risley). Tribology committees were formed, both national and international. Later, the Institution of Mechanical Engineers, which had already sponsored in 1937 a "General Discussion on Lubrication and Lubricants" and had followed this up twenty years later by another conference on "Lubrication and Wear" (organised jointly with the American Society of Mechanical Engineers), set up a Tribology Trust which has made annual awards (gold, silver and bronze medals) since 1972. Also in 1966, a news sheet called Tribology News was launched. A flood of publications and conferences was unleashed. 'Tribology' had arrived.

In 1969, Professor Dowson, who is the founder and director of the Institute of Tribology in the University of Leeds, decided to write a textbook on the subject with an opening chapter on its history. This 'chapter' grew to become the present book of 677 pages.

Looked at in a down to earth man- ner, friction between solid bodies can either be unlubricated or lubricated, and in the latter case it depends on the operating conditions whether the film of lubricant is thick enough to sustain hydrodynamic lubrication-also called 'thick-film' lubrication-or whether one has to consider 'thin-film' lubrication-where the film of lubricant is not thick enough to allow of hydrodynamic flow. The word 'dry', in connection with unlubricated friction should only be used within inverted commas, because the surfaces of all solid bodies carry layers of one contaminant or another, either oxides or sulphides, or adsorbed or condensed matter. Even if these were removed by volatilisation in an ultra-high vacuum, recontamination of the surfaces, which were made 'naked' by volatilisation, would commence instantaneously.

The case is not analogous to the experiments of Agnes Pockels and Irving Langmuir, who scraped and thereby created a 'naked' water surface simultaneously with the application of an organic liquid. This is not the way in which Professor Dowson has set the scene. He would probably agree, however, that friction between solid bodies is a very complex phenomenon. The 'Jost Committee' rightly said that it is "multi-disciplinary". This has been very little heeded in the literature to which Professor Dowson refers. Even when he approaches the end of his journey through the ages and turns to his own subject of Bio-tribology, he uses the misleading word "cold-welding" for what is in fact the adhesive action of films so extremely thin that internal shear in these films is no longer possible (Lord Rayleigh's celebrated 'cup and saucer' experiment).

Throughout the book there is a great deal of confusion between adhesion and cohesion. The wide use of Johansson thickness gauges does certainly not support Professor Dowson's claim of the "cold-welding" of like metals, within the true meaning of the term "welding' as an interpenetration of crystal grains. True, each gauge block is coated with lanolin before they are wrung together, but the process of wringing them together is necessary to make the residual film thin enough for strong adhesion. In this context, Amontons (p154) had coated his blocks of either copper, or iron, or lead, or wood with cart grease, not necessarily with "old pork fat". Amontons himself said ". . . enduits de vieux-oingt". The other blocks "of similar materials and different sizes" which were loaded against the greased ones were ungreased. Nowhere is there any mention of the significance of Amontons' Law as a wear criterion and its importance for the safe operation of machinery.
Neither is it Professor Dowson's thesis that it now seems that Sir William Hardy's introduction of the term 'boundary lubrication' was perhaps unfortunate, particularly if it is used to differentiate qualitatively between materials which function by the same mechanism though with marked quantitative differences, such as additives for so-called 'boundary lubricants' and additives for 'extreme pressure lubricants'. Similarly, referring to the chapter on wear, the important qualitative difference is between "mild wear" and "catastrophic wear" and not between "adhesive" and "abrasive wear".

Professor Dowson has included in his account 16 pages of history of the petroleum industry and of the origins of the major oil companies. John D. Rockefeller was indeed a dominant figure for the greater part of his life. He became a philanthropist at the end of his business career, and for many years, the Rockefeller Foundation did a great deal for the promotion of some outstanding scientific research by enabling promising young scientists to spend one year's leave of absence working with people, such as Lord Rutherford, Niels Bohr, Enrico Fermi, Otto Stern, to name but a few.

The petroleum industry discontinued some years ago the use of 'a-hole-in-apot' viscometers, such as the Redwood, or Saybolt, or Engler, and nowadays uses glass capillary viscometers. Incidentally, the c-g-s- unit of kinematic viscosity is "one Stokes" and not "one stoke". The SAE classification of lubricating oils concerns their viscosity levels and has nothing to do with the dependence of their viscosity on temperature. Even Dean and Davis's 'viscosity index' (VI) only compares the viscosity-temperature dependence of a lubricating oil with that of two other lubricating oils, one of which is a Pennsylvanian oil which has a comparatively very flat viscosity-temperature curve, whereas the other one is a Gulf Coast oil which has a relatively very steep viscosity-temperature curve. Therefore, the VI-numbers assigned to these two types of comparison oils were arbitrarily taken as respectively 100 and 0 . This was an important marketing asset in the days when only one of the American oil companies had a monopoly on Pennsylvanian Brightstock, which was added to petroleum distillation cuts and raffinates as a VIimprover. With the advent of mineral oil-soluble polymers, values of VI greater than 100 could be attained, and the Dean and Davis scale cannot be used here. For these values of VI above 100 , W. A. Wright constructed a different VI-scale. The Standard Methods of Testing Petroleum and its Products of the Institute of Petroleum, the American Society for Testing $\mathrm{Ma}-$ 
terials, and ISO have therefore given since 1966 "two procedures" for calculating VI, one for values between 0 and 100 and, if calculation should indicate a higher value, another one for values above 100 .

Professor Dowson explains in his introductory chapter the chronological "Structure of the book", which is divided into 11 chapters, and his belief in "the wisdom of the 50-year rule", in connection with chapter 11 which has the heading: "Towards tribology: 1925 -the present". The "50-year rule" is Professor Dowson's own variation on someone else's comment that ". . . a wise historian usually stops $20-30$ years before his own time, because he cannot see the wood for the trees; the so-called thirty-year rule". The book has an appendix of 25 biographical sketches which were modelled on a book by one F. R. Archibald.

The book is remarkably free from misprints. There are the odd ones, but they are few and far between, although it is a little startling to find on p443, for instance, $-11.8^{\circ} \mathrm{C}$ as the conversion of $0^{\circ} \mathrm{F}$, when the right figure of $-17.8^{\circ} \mathrm{C}$ is given 5 lines further down; that $121.1^{\circ} \mathrm{F}$ is given on $\mathrm{p} 30$ instead of $119.1^{\circ} \mathrm{F}$ as the conversion of $49.5^{\circ} \mathrm{C}$ is less easily explained; nor that 0.001 $\mathrm{oz}$ is said to be equal to $0.038 \mathrm{~g}$, whichever kind of ounce it may be. But these are details. What is disturbing are the many mistakes both in the body of the text and in the "chronological tables".

\section{Bourgeois chemist}

\section{Colin A. Russell}

Gay-Lussac: Scientist and Bourgeois. By Maurice P. Crosland. Pp. 333. (Cambridge University Press: Cambridge, 1978.) $£ 15$.

DeCEMBer, 1978, was a busy one for chemical historians. The bicentenary celebrations of Humphry Davy's birth were followed by similar festivities in honour of the French chemist, Joseph Louis Gay-Lussac. Both men were born in December, 1778, though in the country of his birth Davy is much better known. Although equally distinguished for his chemical work, GayLussac has had to wait until his bicentenary for a full length biographical treatment in English. The urgent need for such a book has now been met by the timely appearance of this study by Professor Maurice Crosland.

To most modern chemists, GayLussac is merely a name associated
This is not the time and place to list them all. A few randomly chosen examples must suffice here. Lord Rutherford discovered the atomic nucleus in 1911. In 1919 has great achievement was the 'splitting of the atom'. He coined the name 'proton' for the positive hydrogen ion because, before the discovery of the neutron in 1932 , he considered protons and electrons to be the elementary particles of the atomic nucleus. C. 'T. R. Wilson's cloud chamber dates from 1897; and 1926, not 1924, is the date for Schrödinger's wave mechanics. The name of the discoverer of X-rays was Wilhelm Conrad Röntgen and not "Wilhelm von Röntgen". Sir William Hardy and Philip Bowden were members of the Senior Common Room of the same Cambridge College, Gonville and Caius.

The chronological tables are not without their own mysteries. In the juxtaposition of "Political and social events", "General, technical and scientific developments", and "Tribology", one wonders why the "Tribology" column was chosen to record such events as Henry Deterding assuming "control of Royal Dutch Company", the "merger between Royal Dutch and Shell", and the move of the Timken Company to Canton, Ohio.

Robert Schnurmann is Honorary Research Fellow in the Department of Chemical Engineering at the University of Birmingham, UK.

with two or at the most three notable achievements, the best known of which is his Law of Combining Volumes (1808), asserting a simple ratio between volumes of combining gases and their products (if gaseous). He has also been associated with the law connecting gaseous volume with temperature, though more frequently this is referred to as "Charles' Law"; in fact Gay-Lussac was the first to publish (1802), but his experiments were based on earlier work by J. A. C. Charles. Thirdly, chemists will recall the "GayLussac tower" as part of the lead chamber process for making sulphuric acid, being a device for recovering nitrogen oxides from the effluent gas. The last Gay-Lussac tower that I know of in this country disappeared when the final lead chamber plant was dismantled about four years ago, so a further association with Gay-Lussac will be lost to future chemists.

However, as Crosland has been at pains to show, Gay-Lussac is worthy of commemoration for much more than this. His Law of Gaseous Volumes not only provided the foundation on which Avogadro and Cannizzaro were later to build their own theoretical structures; it seems that it confirmed to its
Your Professional Library... What's Missing?

\section{Biopolymers}

0006-3525

An International Journal of Research on Biological Molecules

Editor: Murray Goodman

Original research papers on the physical chemistry, organic chemistry and biophysics of biological macromolecules. Covers monomers, oligomers, and molecules which interact with biopolymers.

Volume 18, Monthly $\$ 242.00$

Outside U.S. add $\$ 18.00$ for postage and handling.

\section{Biotechnology and Bioengineering}

\section{Editor: Elmer L. Gaden, Jr.}

An international forum for original research on all aspects of biochemical and microbial technology, including products, process development and design, and equipment.

Volume 21, Monthly, plus Symposium Computer Applications in Fermentation Technology $\$ 140.00$

Outside U.S. add $\$ 16.00$ for postage and handling.

\section{Developmental \\ Psychobiology}

$0012-1630$

\section{Editor-in-Chief: Gilbert Meier}

Original results on physiological, environmental, genetic and behavioral functioning of humans and other animals during early stages of life. Assesses long-term developments.

Volume 12, Bimonthly $\$ 55.00$

Outside U.S. add $\$ 9.00$ for postage and handling.

\section{Journal of Biomedical} Materials Research

The Official Journal of the Society for Biomaterials and the European Society for Biomaterials

\section{Editor-in-Chief: A. Norman Cranin}

Evaluates preparation methods and use of plastics, ceramics, metals, and reprocessed animal tissue in fabrication of equipment and instrumentation used in medicine and biology.

Volume 13, Bimonthly $\$ 115.00$

Outside U.S. add $\$ 10.00$ for postage and handling.

\section{Journal of Neurobiology $0022-3034$}

Editor-in-Chief: Graham Hoyle

Publishes papers covering a wide range of neuroscience. All types of organism and techniques of research are acceptable that bear upon the common theme of relating cellular events to behavior.

Volume 10, Bimonthly $\$ 60.00$

Outside U.S. add $\$ 9.00$ for postage and handling.

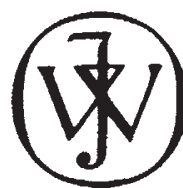

JOHN WILFY \& SOUS

605 Third Avenue

New York NY 10016 U.S.A.

Baffins Lane, Chichester Sussex P019 10D, England 